\title{
SoilErosionDB: A global database for surface runoff and soil erosion evaluation
}

\author{
Jinshi Jian ${ }^{1 \star}$, Xuan $\mathrm{Du}^{2 \star}$, Ryan D. Stewart ${ }^{3}$, Zeli Tan ${ }^{4}$, Ben Bond-Lamberty ${ }^{1}$ \\ ${ }^{1}$ Pacific Northwest National Laboratory, Joint Global Change Research Institute at the University of \\ 5 Maryland-College Park, 5825 University Research Court, Suite 3500, College Park, MD 20740, USA \\ ${ }^{2}$ Department of Hydraulic Engineering, Yangling Vocational \& Technical College, Yang Ling, Shaanxi, \\ China \\ ${ }^{3}$ School of Plant and Environmental Sciences, Virginia Tech, Blacksburg, VA, USA \\ ${ }^{4}$ Pacific Northwest National Laboratory, Richland, WA, USA \\ Correspondence to: Jinshi Jian (jinshi@vt.edu)
}

$\star$ These authors contributed equally to this work

\begin{abstract}
Soil erosion is a major threat to soil resources, continuing to cause environmental degradation and social poverty in many parts of the world. Many field and laboratory experiments have been performed over the past century to study spatio-temporal patterns of soil erosion caused by surface runoff under different environmental conditions. However, these historical data have never been integrated together in a way that can inform current and future efforts to understand and model soil erosion at different scales. Here, we designed a database (SoilErosionDB) to compile field and laboratory measurements of soil erosion caused by surface runoff, with data coming from sites across the globe. The SoilErosionDB includes 18 columns for soil erosion related indicators and 73 columns for background information that describe factors such as latitude, longitude, climate, elevation, and soil type. Currently, measurements from 99 geographic sites and 22 countries around the world have been compiled into SoilErosionDB. We provide examples of linking SoilErosionDB with an external climate dataset and using annual precipitation to explain annual soil erosion variability under different environmental conditions.
\end{abstract}

25 All data and code to reproduce the results in this study can be found at: Jian, J., Du, X., Stewart, R., Tan, Z. and Bond-Lamberty, B.: jinshijian/SoilErosionDB: First release of SoilErosionDB, Zenodo, doi:10.5281/zenodo.4030875, 2020b. All data are also available through GitHub: https://github.com/jinshijian/SoilErosionDB.

Keywords: Surface runoff, soil erosion, nutrient leaching, database 


\section{Background}

Soil is an essential natural resource for human sustainable development that is continually threatened by erosion and related land degradation processes (Borrelli et al., 2017; Poesen, 2017). Soil erosion is a geomorphic process that occurs when soil particles, soil aggregates, organic matter, and rock fragments detach from their original positions and become transported to other locations (Morgan, 1988; Toy et al., 2002). Erosion is a naturally occurring process affected by both abiotic (e.g., rainfall, runoff, wind, and snow avalanches) and biotic drivers (e.g., animal trampling and tree fall), and may have significant consequences for carbon cycling (Berhe et al., 2007; Ito, 2007; Lal, 2003; Tan et al., 2020; Yue et al., 2016).

Erosion rates have been substantially increased by human activities such as cropland cultivation, mining, building construction, and deforestation (Borrelli et al., 2017; García-Ruiz et al., 2015; Poesen, 2017; Vanwalleghem et al., 2017). For instance, large-scale farmland development in forested and grass-covered prairies of the United States of America led to the Black Dust Bowl of the 1930s, resulting in widespread ecosystem damage and economic losses (Schubert et al., 2004). In China, population and demographic shifts have increased demand for food and other resources, leading to increases in cultivated croplands and concomitant soil erosion problems (Guo et al., 2015; Xu et al., 2010; Zhang et al., 2012; Zhao et al., 2013).

Many field and lab experiments have characterized soil erosion under different environmental conditions. Some have utilized soil erosion runoff plots, with nations and regions such as the USA ( $>10,000$ plots), Europe ( $>8.000$ plots), Brazil (3,525 plots) and Brazil ( $>2,500$ plots) all having widespread installations (Poesen, 2017). These experiments have led to more than 31,000 different peer-reviewed studies (searched at https://www.sciencedirect.com using "Erosion and runoff" as keyword). However, there has not yet been a successful effort to compile the data from those studies into a single and coherent dataset.

To bridge this research gap, we developed a global soil erosion database (SoilErosionDB) for standardizing and compiling historical soil erosion related measurements together. The database can be used to support evaluation and parameterization of global soil erosion models, statistical modeling, non-point pollution evaluation, as well as cropland management recommendation. It can also be used to perform synthesis analyses, such as meta-analyses, and may inspire future efforts to better understand spatial and temporal patterns of soil erosion. 


\section{Methods}

We designed the SoilErosionDB following FAIR protocols, i.e., Findable, Accessible, Interoperable, and Reusable (Wilkinson et al., 2016). All data, quality assurance/quality control (QA/QC) code, and analysis code are immediately available through a GitHub repository (https://github.com/jinshijian/SoilErosionDB), and each release will be issued a DOI through Zenodo to ensure reusability. The version format follows an " $x \cdot y \cdot z$ " format, where $x$ is the major version number, $y$ is the minor version number, and $z$ is the patch number. We update the major version number only if the database changes its structure; we expect this to happen at an approximately decadal time step. We update the minor version number whenever the database has a significant data update; this usually happens at annual time steps. The patch number will be updated relatively often, whenever the database has an important documentation update or data correction. We also made efforts to ensure interoperability so that SoilErosionDB could easily link to external datasets. For an example of linking SoilErosionDB to an external climate dataset please see "4. Linkages to external data sources" section below.

\subsection{Publication collection}

Publications were collected during an online literature search using "runoff, erosion" as keyword in ScienceDirect (https://www.sciencedirect.com/). We had no restrictions on literature types, i.e., both peer-reviewed articles and no-peer-reviewed articles such as theses, dissertations, and conference collections were included. We initiated our search on January 10, 2020 and found 31,235 papers, with an increasing number of published papers by year (Figure 1a). The following criteria were used to determine whether a article should be included in the SoilErosionDB: (1) measurements were measured in the field, at the laboratory with rainfall simulation experiment, or from indirect methods (Table 1); (2) soil erosion was reported in units that could be converted to t ha $^{-1}$ year $^{-1}$ or $\mathrm{g} \mathrm{m}^{-2}$ hour $^{-1}$; and (3) articles were published in English or Chinese language journals after 1960. We included no other filtering criteria or restrictions to the literature. Note that we did not include a constraint for leaching data because a variety of leaching types (e.g., soil organic carbon loss, organic matter losses, and total nitrogen loss) were reported in papers, with those measurements reported in different units.

\subsection{Database structure design}

The SoilErosionDB (i.e., "SoilErosionDB.xlsx" file in the GitHub repository) has 12 data sheets, and the core part is the "SoilErosionDB" data sheet, with 18 columns for soil erosion, surface runoff, and nutrient leaching records (Table 2) and 73 columns for background information (Table 3). The "DataBase_fields" sheet describes all 91 columns in the "SoilErosionDB" data sheet. The 
"UnitsConverter" sheet contains a 'units converter' to standardize all surface runoff and soil erosion measurements into the same unit (i.e., soil erosion in units of $\mathrm{t} / \mathrm{ha} / \mathrm{yr}$ or $\mathrm{g} / \mathrm{m}^{2} / \mathrm{hr}$; runoff in units of $\mathrm{mm} / \mathrm{yr}$ or $\mathrm{mm} / \mathrm{hr}$ ). The "CountryCode" sheet holds the international country code for the usage of Site_ID. The "Slope" sheet provides the converter of transforming slope from $\%$ to ${ }^{\circ}$. The "Quality_flag" sheet describes the quality control flag of measurements collected from papers (see Table 4 for details). The "Meas_method" sheet describes soil erosion measurement methods reported in papers (see Table 1 for details). The "Biome" sheet describes different biome types. The "IGBP" sheet describes all 20 International Geosphere-Biosphere Programme (IGBP) (Townshend, 1992) vegetation types reported in papers. The "Manipulation" sheet includes description and comments about 17 manipulation types used in the SoilErosionDB (see Table 5 for details). The "ReferenceList" sheet holds all reference details for all papers we compiled into the SoilErosionDB; and the "LiteratureSearch" sheets describes literature search details for the SoilErosion $D B$, such that users can reproduce the literature search results based on the description.

We read through each publication and compiled measurements and background information into SoilErosionDB. Currently we have collected and processed data from 124 papers that included measurements taken between 1980 and 2017 (Figure 1b). Each column in SoilErosionDB corresponds to either background information, surface runoff, soil erosion, or nutrient leaching indicator. When sites' location (latitude and longitude) was not reported, we estimated site coordinates according to the site name or the maps provided in the paper. For the soil erosionrelated indicators, i.e., surface runoff, soil erosion, and nutrient leaching, data were either directly read from tables or digitized from figures. We used Data Thief (version III) (Flower et al., 2016) whenever we had to obtain the values from figures. Replications and standard deviation (SD) information were usually directly obtained from the original papers, however, sometimes confidence interval $(\mathrm{CI})$, coefficient of variation $(\mathrm{CV})$, or standard error (SE) was reported rather than SD, we calculated SD using equations 1-3 of (Jian et al., 2020a).

\subsection{Surface runoff, soil erosion, and nutrient leaching measurements}

The field, unit, and explanation about the surface runoff, soil erosion, and nutrient leaching measurements are presented in Table 2. It should be noted that SoilErosionDB has been designed to hold surface runoff, leaching and soil erosion measurements in terms of both annual amounts and instantaneous rates. However, nutrient leaching was organized in a different way, where the "Leaching" column holds values, the "Leaching_unit" holds the unit of measurement reported in the original paper, and the "Leaching_type" column records the leaching type reported in the original paper.

\subsection{Background information}


Background information (Table 3) includes descriptive data about sites and experimental design. Soil erosion measurement methods, quality control flag, and manipulation are further described in Tables 1, Table 4, and Table 5. Specifically, Table 1 describes 16 soil erosion measurement methods reported in literature; Table 4 describes 10 quality control flags to help the developer record necessary information for quality control. Table 5 describes manipulation information, which is useful for the further analysis about how treatment affects surface runoff and soil erosion.

\section{Technical validation}

We carefully checked the data with the original paper to ensure the fidelity. We used the Mendeley bibliography management software (https://www.mendeley.com) to ensure papers were not compiled into the database multiple times by different contributors. Each paper was first carefully read by the data collector, and any useful records were compiled into SoilErosionDB. Then a data quality checker compared the data in the database against the original paper. Specially, we paid attention to the methods sections, figures, and tables, where most of the surface runoff, soil erosion, nutrient leaching, and background information were located.

In addition, we developed an $\mathrm{R}$ markdown file (ErosionDB_validation.Rmd in the Github repository) to examine the data quality of SoilErosionDB. The file was created using $\mathrm{R}$ Version 3.6.1 (R Core Team, 2020). For the latitude and longitude inputs, we plotted sites by individual country (currently a total of 22 countries, Figure 2), then compared the sites with that country's 145 boundaries to ensure that no sites fell outside. For any sites that appeared to be mislocated, we went back to the original paper and corrected the coordinates in the database. For all numeric columns in the SoilErosionDB (except "Unique_ID" and "Study_number"), we plotted histograms for each column, and checked whether extreme values were included in the database. Figure 3 shows an example using the histograms of annual surface runoff and annual soil erosion.

\section{Linkages to external data sources}

Potentially important climate data (e.g., temperature and precipitation) are important factors affecting surface runoff and soil erosion; however, many papers did not report that information. Therefore, we linked the SoilErosionDB with a $0.5^{\circ} \times 0.5^{\circ}$ resolution global climate data product (Willmott and C. J., 2000) to obtain annual temperature, mean annual temperature (MAT), annual precipitation, and mean annual precipitation (MAP) based on site latitude and longitude. The MAT and MAP were calculated based on records between 1961 and 2015.

The results showed that temperature and precipitation data from the global climate dataset are highly correlated with that reported in the literature (Figure 4). Furthermore, we analyzed whether annual precipitation obtained from the external climate dataset can be used to explain annual soil 
erosion variability in SoilErosionDB. We found that annual precipitation from the global climate dataset can explain $\sim 7 \%$ of variability in annual soil erosion (Figure 5, $\mathrm{R}^{2}=0.07, \mathrm{p}=0.01$ ). We presume that linking SoilErosionDB with other external data sources, e.g., leaf area index, vegetation type, climate type, and soil properties, can lead to increased explanatory power for spatial and temporal variability of soil erosion.

\section{Data and code availability}

The data and source code are available through GitHub (https://github.com/jinshijian/SoilErosionDB) and Zenodo (Jian et al., 2020b) (http://doi.org/10.5281/zenodo.4030875). The code is described in details with instructions for users. Generally, a markdown file (SoilErosionDB.Rmd) were created, which generated all figures (Figure 1 to Figure 5) and described the analysis for this study. All the data processing and data visualization were conducted using $\mathrm{R}$ (version 3.6.1).

\section{Usage notes}

We suggest users download the data and code directly from Zenodo (http://doi.org/10.5281/zenodo.4030875), as Zenodo provides DOI and generates the same results 175 for all users. Another advantage of using data and code from Zenodo is that it avoids any run errors caused due to adding new measurements during database updating. On the other hand, the data and code in the GitHub are for development purposes. In addition, as new records are added to the database, output results may differ from those generated using older versions, and may even cause run errors. The users are encouraged to contact the SoilErosionDB development team before using the data from Zenodo for analysis. We recommend that users contribute as a data quality checker is a great first step to understand the data; with the provided R code, users could explore the database as the code explained the analysis and the data in details.

\section{Future directions and contribution notes}

We have decided to share this work at this initial database development stage for two reasons: 1)

we want to receive feedback from the community about how to improve the data structure to ensure optimal usage; 2) the large number of potentially relevant papers that have been or will be published makes it important to expand the development team. Thus, we welcome and invite scientists and data users who are interested in developing SoilErosionDB to download the dataset and consider contributing published or unpublished data. Our long-term goal is to update SoilErosion $D B$ by including measurements from newly published papers every year. 


\section{Acknowledgements}

Xuan Du was supported by the Yangling Vocational \& Technical College, under grant number: A2019009. Jinshi Jian was supported by the US Department of Energy, Office of Science, 195 Biological and Environmental Research as part of the Terrestrial Ecosystem Sciences Program, under contract DE-AC05-76RL01830. Ryan Stewart was supported by the Virginia Agricultural Experiment Station and the Hatch Program of the National Institute of Food and Agriculture, U.S. Department of Agriculture. All the data and code to support this analysis can be found at:https://github.com/jinshijian/SoilErosionDB and http://doi.org/10.5281/zenodo.4030875. This

200 database can be used for research, academic, individual, or commercial usage, and can be sold or repackaged without written permission.

\section{Author contributions}

Xuan Du and Jinshi Jian conceived the design of the data framework, compiled the data from papers to the SoilErosionDB. Xuan Du and Jinshi Jian wrote the manuscript, and all authors revised and approved the manuscript.

\section{Competing interests}

The authors declare no conflicts of interest. 
Figures and Tables

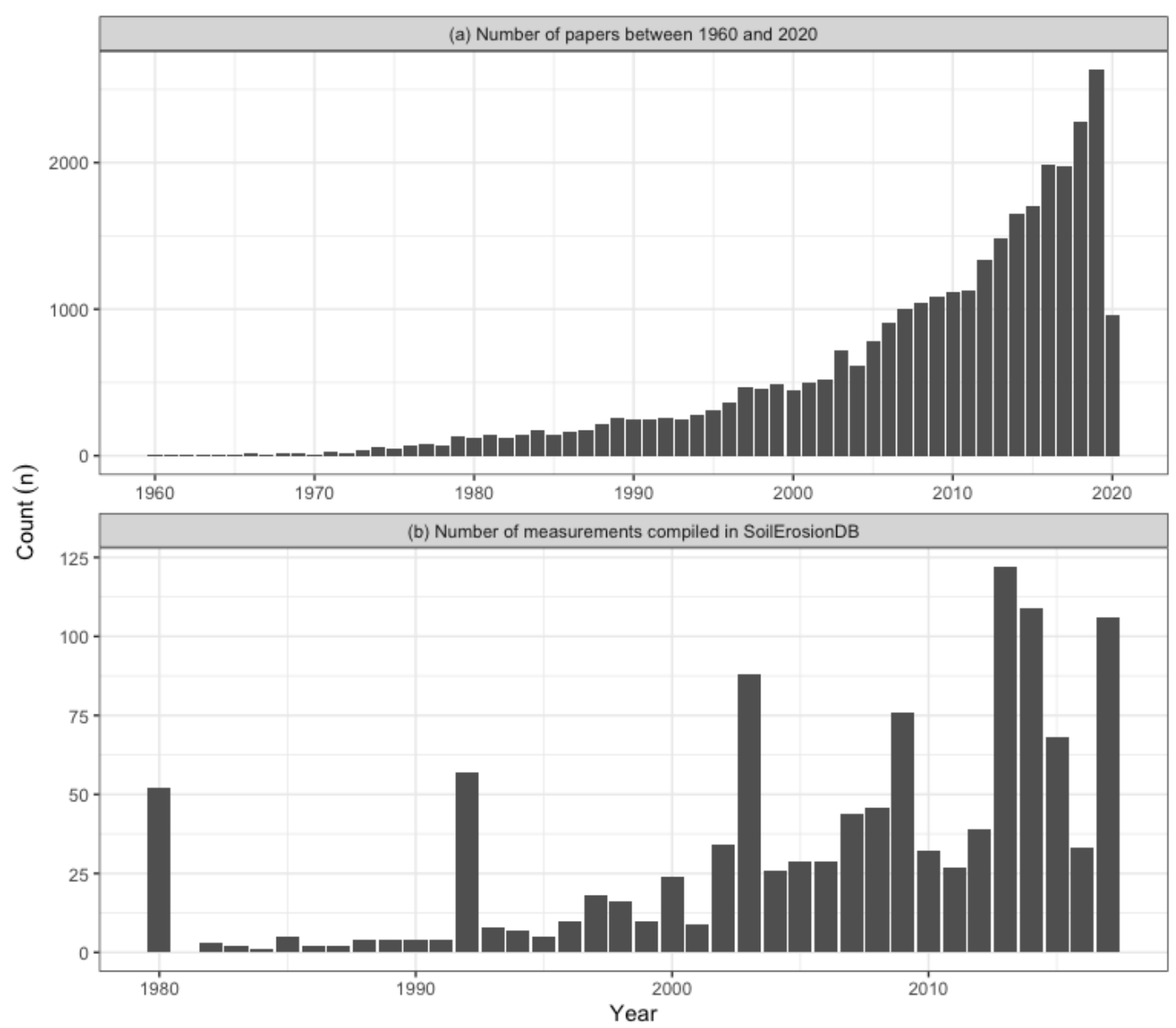

210 Figure 1. Summary of (a) studies published on the topics of surface runoff, soil erosion, and leaching between 1960 and 2020; and (b) temporal distribution of soil erosion measurements from 124 papers compiled into SoilErosionDB. The trend shows that more and more runoff and erosion related studies are published. 


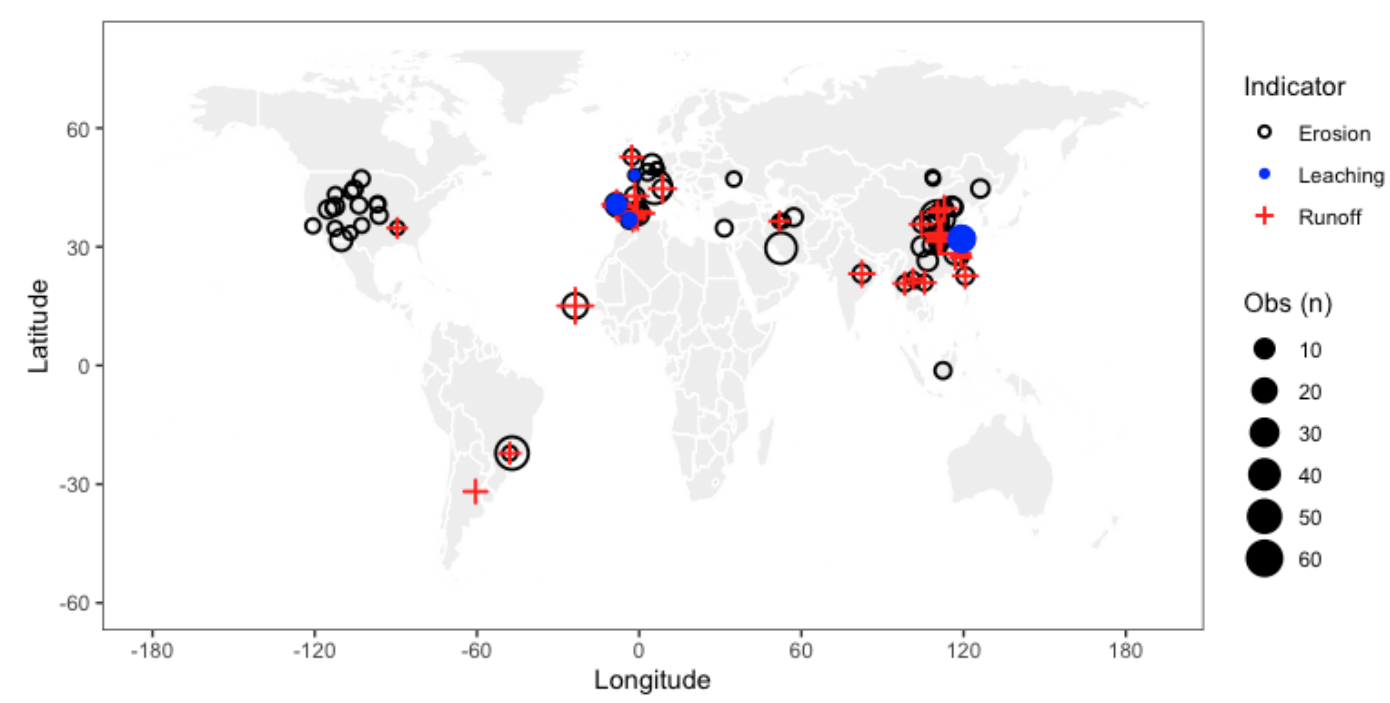

215 Figure 2. Spatial distribution of surface runoff, soil erosion, and leaching sites. The size of circles represents the sample size at each measurement site (i.e., bigger circles represent more data). 

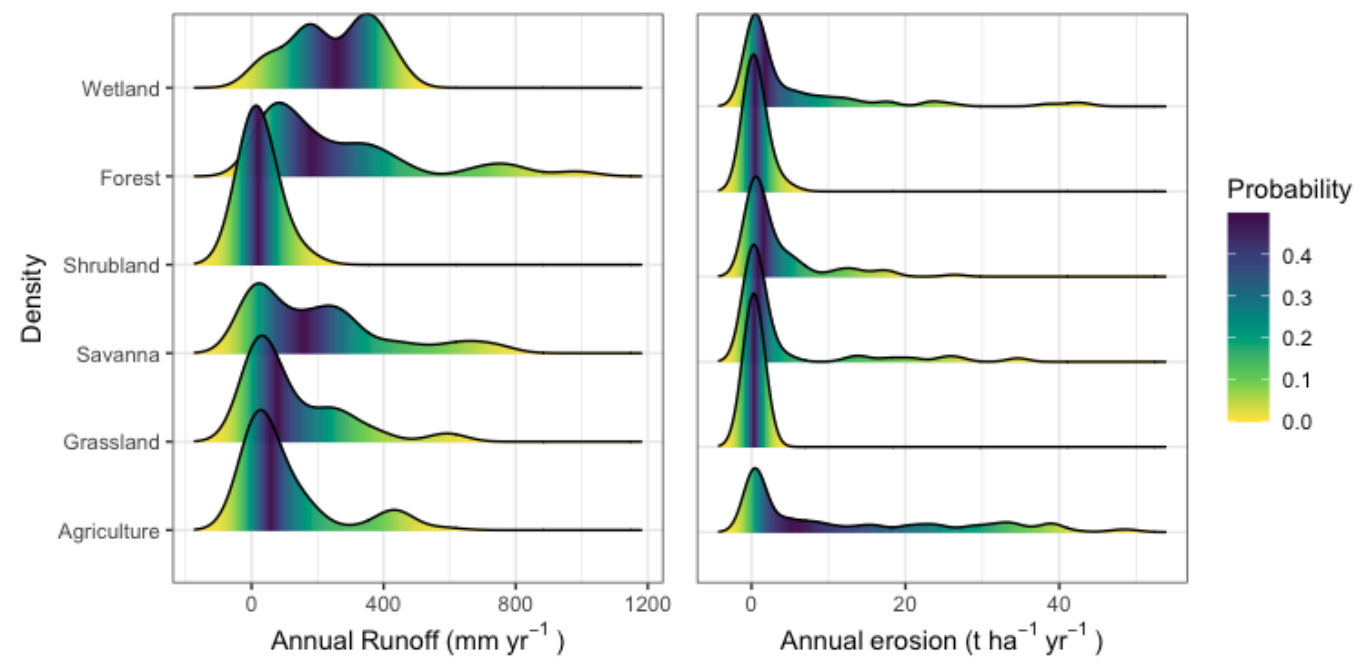

Figure 3. Distribution of surface runoff and soil erosion values in the global soil erosion database (SoilErosionDB). A few soil erosion data points with rates $>50 \mathrm{t} \mathrm{ha}^{-1} \mathrm{yr}^{-1}$ were not shown. 


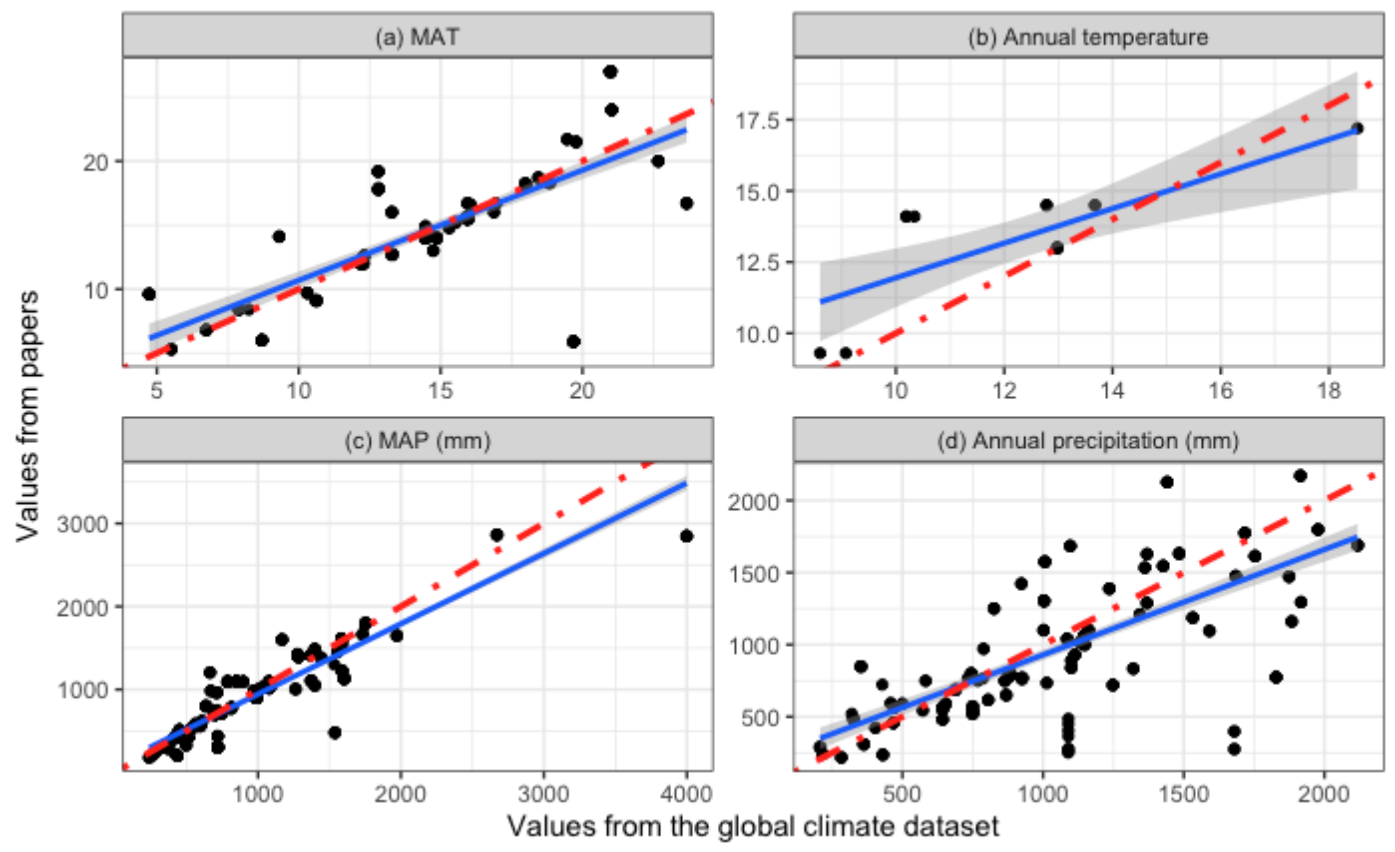

Figure 4. Relationship between (a and c) mean annual temperature/precipitation (between 1960 and 2017, MAT or MAP) reported in the papers and that from the global climate dataset (Willmott and C. J., 2000); and (b and d) annual temperature/precipitation obtained from papers vs. values obtained from the global climate dataset (Willmott and C. J., 2000). The linear regression lines (solid blue) are very close to the 1:1 lines (dashed red), indicating a good agreement between air temperature (precipitation) reported in papers and values obtained from the global climate dataset. Note that the shaded regions around the regression lines indicate $95 \%$ confidence intervals. 


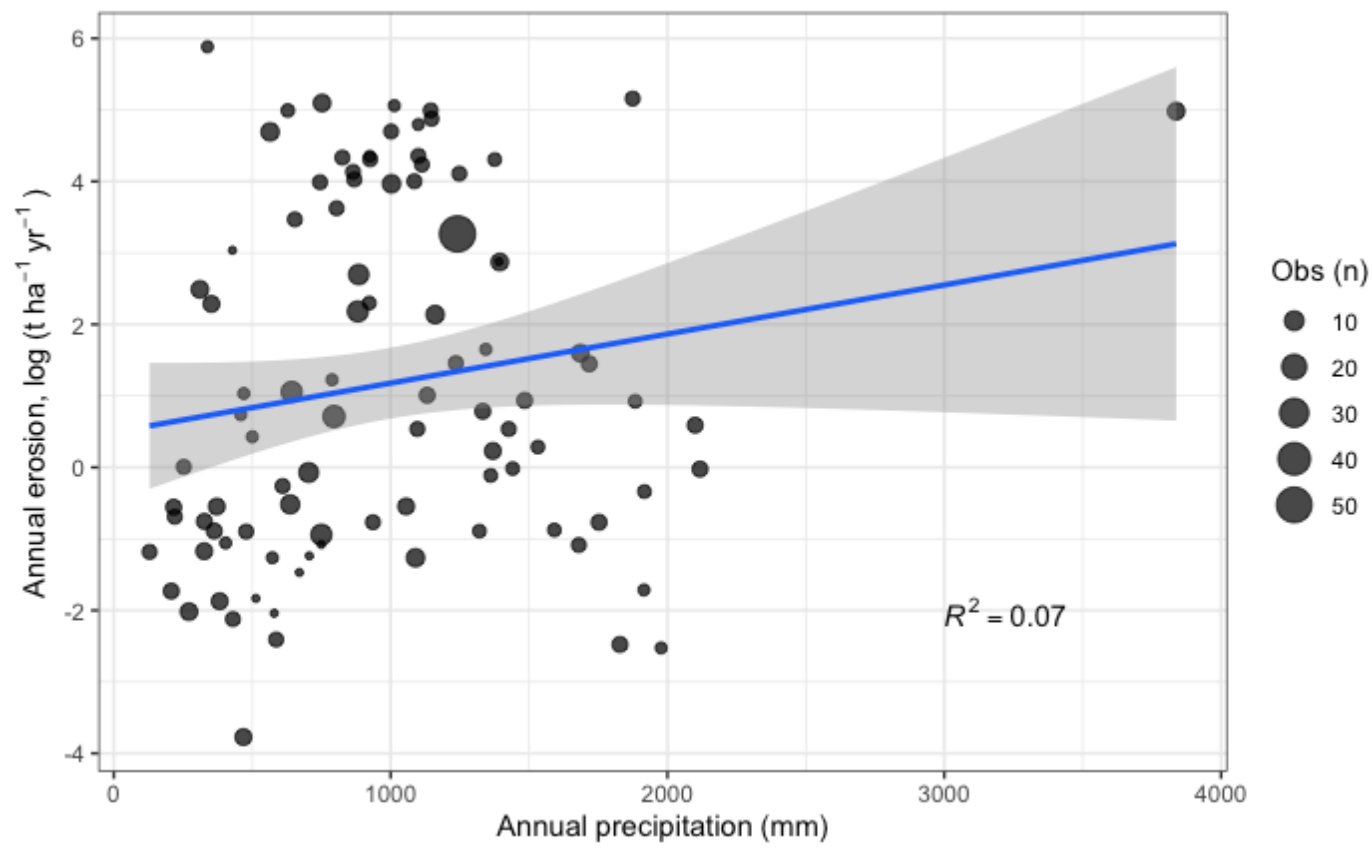

Figure 5. Relationship between annual soil erosion (log transferred, $\mathrm{t} \mathrm{ha}^{-1} \mathrm{yr}^{-1}$ ) and annual precipitation $(\mathrm{mm})$. The linear regression (solid blue line) showed that annual precipitation can explain $\sim 7 \%$ annual soil erosion variability $\left(\mathrm{R}^{2}\right.$ of the regression $=0.07$ and $\mathrm{p}$ of slope $\left.=0.01\right)$. Note that the shaded region around the regression line indicates $95 \%$ confidence intervals. We used a Cook's distance with threshold of 0.5 to detect any influential outliers, but no data points were found to be outliers. 
235 Table 1. Soil erosion measurement methods included in the global soil erosion database (SoilErosionDB).

\begin{tabular}{|l|l|l|}
\hline Method_Group & Method & Explanation \\
\hline \multirow{5}{*}{} & Plot & E.g., standard runoff plot $(20 \mathrm{~m} \times 5 \mathrm{~m})$ \\
\cline { 2 - 3 } & Morphology & Morphological transects \\
\cline { 2 - 3 } & Erosion pins & Erosion pins \\
\cline { 2 - 3 } & Profilemeters & Profilemeters \\
\cline { 2 - 3 } & Caesium 137 & Measuring soil erosion rate using Caesium137 \\
\cline { 2 - 3 } Field measurement & Be7 & Measuring soil erosion rate using Be7 \\
\cline { 2 - 3 } Lab rainfall & Catchment & Experimental catchment/watershed \\
\cline { 2 - 3 } simulation & Reservoir surveys & Bathymetrical surveys of reservoirs \\
\hline \multirow{5}{*}{ Indirect methods } & Lab rainfall simulation & Rainfall simulation experiment in the field \\
\hline \multirow{5}{*}{ Other } & Roinfall simulation experiment in the laboratory \\
\hline & Gopography & $\begin{array}{l}\text { Modelling, e.g., soil erosion rate calculated by the } \\
\text { Revised Universal Soil Loss Equation (RUSLE) } \\
\text { model (Foster et al., 2000; Nam et al., 2003) }\end{array}$ \\
\cline { 2 - 3 } & Other & Soil erosion estimated from remote sensing \\
\cline { 2 - 3 } & Remote sensing & Soil erosion estimated based on GIS technology \\
\hline
\end{tabular}


Table 2. Description and categories of surface runoff and soil erosion related metrics in the global soil erosion database (SoilErosionDB).

\begin{tabular}{|c|c|c|}
\hline Field & Unit & Explanation \\
\hline ER_annual & $\mathrm{t} / \mathrm{ha} / \mathrm{yr}$ & Annual soil erosion amount in unit of $\mathrm{t} / \mathrm{ha} / \mathrm{yr}$ \\
\hline ER_annual_err & $\mathrm{t} / \mathrm{ha} / \mathrm{yr}$ & Annual soil erosion error (plot-to-plot) \\
\hline ER_interann_err & $\mathrm{t} / \mathrm{ha} / \mathrm{yr}$ & $\begin{array}{l}\text { Interannual error reported for annual soil erosion. This is sometimes } \\
\text { reported in the article }\end{array}$ \\
\hline ER_SD & $\mathrm{t} / \mathrm{ha} / \mathrm{yr}$ & Standard deviation (typically plot-to-plot) for annual soil erosion \\
\hline ER_max & $\mathrm{g} / \mathrm{m}^{2} / \mathrm{h}$ & Maximum soil erosion rate \\
\hline ER_maxday & No units & Day of year maximum soil erosion happen \\
\hline ER_M_Area_h & $\mathrm{g} / \mathrm{m}^{2} / \mathrm{hr}$ & Soil erosion rate in unit of $\mathrm{g} / \mathrm{m}^{2} / \mathrm{hr}$ \\
\hline ER_M_Volume & $\mathrm{g} / \mathrm{L}$ & Soil erosion rate in unit of $\mathrm{g} / \mathrm{L}$ \\
\hline Runoff_annual & $\mathrm{mm} / \mathrm{yr}$ & Annual Runoff amount in unit of $\mathrm{mm} / \mathrm{yr}$ \\
\hline Runoff_err & $\mathrm{mm} / \mathrm{yr}$ & Error (typically plot-to-plot) for annual runoff \\
\hline Runoff_SD & $\mathrm{mm} / \mathrm{yr}$ & Annual runoff standard deviation (plot-to-plot) \\
\hline Runoff_max & $\mathrm{mm} / \mathrm{h}$ & Maximum runoff rate \\
\hline Runoff_max_day & No units & Day of year when maximum runoff happen \\
\hline Runoff_mm_h & $\mathrm{mm} / \mathrm{h}$ & Runoff rate in unit of $\mathrm{mm} / \mathrm{h}$ \\
\hline Leaching & Units vary & Annual leaching amount or rate \\
\hline Leaching_unit & Units vary & Annual leaching error (typically plot-to-plot) for \\
\hline Leaching_SD & Units vary & Annual leaching standard deviation (plot-to-plot) \\
\hline Leaching_type & No units & Leaching type (e.g., phosphorus, organic matter, organic carbon) \\
\hline
\end{tabular}


Table 3. Description and categories of background fields in the global soil erosion database (SoilErosionDB).

\begin{tabular}{|c|c|c|}
\hline Field & Description & Comments \\
\hline Unique_ID & Unique ID & A numeric unique ID number \\
\hline Entry_date & Data entry date & When data was inputted, YYYY/MM/DD \\
\hline Study_number & Paper identical ID & A numeric ID for each paper in SoilErosionDB \\
\hline Author & First author's family name & \\
\hline Duplicate_record & Duplicate sigh & $\begin{array}{l}\text { If this study is a known duplicate, give the } \\
\text { study number it repeated to }\end{array}$ \\
\hline Quality_flag & Quality flag & Q0-Q10, see Table 4 for details \\
\hline Contributor & Initial of data collector & Initial of data collector, e.g., JJ for Jinshi Jian \\
\hline Checker & Initial of data checker & $\begin{array}{l}\text { Initial of data quality check person, e.g., XD } \\
\text { for Xuan } \mathrm{Du}\end{array}$ \\
\hline Country & Data from which country & \\
\hline Region & Data from which region & Usually, province or state \\
\hline Site_name & Site name of the experiment & \\
\hline Site_ID & Unique Site ID within a study & $\begin{array}{l}\text { It is a combination of country code (see } \\
\text { countrycode sheet), region code, and identify } \\
\text { code (could be site name code, manipulation } \\
\text { code, disturbance code, etc) }\end{array}$ \\
\hline Paper_year & Paper published year & \\
\hline Study_midyear & Year of data measured & \\
\hline YearsOfData & Number of years & $\begin{array}{l}\text { Data averaged from how many years, e.g., } 3 \text { for } \\
\text { average from } 3 \text { years, usually it is } 1 \text { year }\end{array}$ \\
\hline Annual_coverage & Annual coverage & $\begin{array}{l}0-1,0.01 \text { means } \leq 1 \text { day of data, } 1 \text { means } \\
\text { covered at least a whole year, with at least } 12 \\
\text { months of data }\end{array}$ \\
\hline Latitude & Latitude of site & $\circ$ \\
\hline Longitude & Longitude of site & $\circ$ \\
\hline
\end{tabular}




\begin{tabular}{|c|c|c|}
\hline Elevation & Elevation of site & $\mathrm{m}$ \\
\hline MAT & Mean annual temperature & ${ }^{\circ} \mathrm{C}$ \\
\hline MAP & Mean annual precipitation & $\mathrm{mm}$ \\
\hline Study_temp & Annual temperature & ${ }^{\circ} \mathrm{C}$ \\
\hline Study_precip & Annual average precipitation & $\mathrm{mm}$ \\
\hline MPET & $\begin{array}{l}\text { Annual potential } \\
\text { evapotranspiration }\end{array}$ & $\mathrm{mm}$ \\
\hline Biome & Biome classification & $\begin{array}{l}\text { Tropic, subtropic, temperate, Mediterranean, } \\
\text { boreal, arctic etc. }\end{array}$ \\
\hline STIR & Soil tillage intensity rating & \\
\hline Manipulation_age & Years since manipulation & How many years since the manipulation \\
\hline Manipulation & Manipulation & See Table 5 for details \\
\hline Manipulation_level & Management level & \\
\hline Ecosystem_age & Year & Age of ecosystem \\
\hline Species & Plant species of site & Latin name of dominant species \\
\hline Leaf_habit & Leaf habit of site & Evergreen, deciduous, or mixed \\
\hline Stage & Stage of site & Aggrading, mature, subjective \\
\hline IGBP & IGBP classification & $\begin{array}{l}\text { The International Geosphere-Biosphere } \\
\text { Programme (IGBP) classification: } \\
\text { https://climatedataguide.ucar.edu/climate- } \\
\text { data/ceres-igbp-land-classification }\end{array}$ \\
\hline Ecosystem_stage & Ecosystem stage & $\begin{array}{l}\text { Ecosystem stage (natural, managed, } \\
\text { unmanaged). Subjective }\end{array}$ \\
\hline LAI & Leaf area index & Hemispheric (one-sided) if possible \\
\hline Soil_family & Soil classification & Soil family, US classification if available \\
\hline Soil_texture & Soil classification & Soil texture, US classification if available \\
\hline Soil_sand & Sand percentage & $\%$ \\
\hline
\end{tabular}




\begin{tabular}{|c|c|c|}
\hline Soil_silt & Silt percentage & $\%$ \\
\hline Soil_clay & Clay percentage & $\%$ \\
\hline Soil_rock & Rock fragment & $\%$ \\
\hline Soil_BD & Soil bulk density & $\mathrm{g} \mathrm{cm}^{-3}$ \\
\hline Soil_pH & Soil pH & Unitless \\
\hline Soil_SAR & Sodic description & Unitless \\
\hline Soil_C_\% & Soil carbon concentration & $\%$ \\
\hline Soil_C_stock & Soil carbon stock & $\mathrm{g} / \mathrm{m}^{2}$ \\
\hline Soil_C_Depth & Soil carbon depth & $\mathrm{cm}$ \\
\hline Soil_N & Soil nitrogen & $\%$ \\
\hline Soil_CN & Soil carbon to nitrogen ratio & Unitless \\
\hline Crust $\%$ & Soil crust & Unitless \\
\hline Ksat & Soil saturated conductivity & $\mathrm{cm} / \mathrm{h}$ \\
\hline $\mathrm{E}$ & $\begin{array}{l}\text { Revised Universal Soil Loss } \\
\text { Equation (RUSLE) model rainfall } \\
\text { factor, energy (Foster et al., 2000; } \\
\text { Nam et al., 2003) }\end{array}$ & MJ ha' ${ }^{-1}$ year $^{-1}$ \\
\hline $\mathrm{I} 30$ & $\begin{array}{l}\text { RUSLE rainfall factor (Foster et } \\
\text { al., 2000; Nam et al., 2003) }\end{array}$ & $\mathrm{mm} \mathrm{h}^{-1}$ \\
\hline EI30_R & $\begin{array}{l}\text { RUSLE rainfall factor (Foster et } \\
\text { al., 2000; Nam et al., 2003) }\end{array}$ & $\mathrm{E} \times \mathrm{I} 30, \mathrm{MJ} \mathrm{mm} \mathrm{h}^{-1} \mathrm{ha}^{-1}$ year $^{-1}$ \\
\hline K & $\begin{array}{l}\text { RUSLE soil erodibility factor } \\
\text { (Foster et al., 2000; Nam et al., } \\
\text { 2003) }\end{array}$ & t-ha-h ha- $1 \mathrm{MJ}^{-1} \mathrm{~mm}^{-1}$ \\
\hline $\mathrm{L}$ & $\begin{array}{l}\text { RUSLE slope length factor (Foster } \\
\text { et al., 2000; Nam et al., 2003) }\end{array}$ & $\mathrm{m}$ \\
\hline Slope & $\begin{array}{l}\text { RUSLE slope factor (Foster et al., } \\
\text { 2000; Nam et al., 2003) }\end{array}$ & $\circ$ \\
\hline
\end{tabular}




\begin{tabular}{|c|c|c|}
\hline Plant_cover_C & $\begin{array}{l}\text { RUSLE plant coverage factor } \\
\text { (Foster et al., 2000; Nam et al., } \\
\text { 2003) }\end{array}$ & $\%$ \\
\hline $\mathrm{P}$ & $\begin{array}{l}\text { RUSLE plant cropland } \\
\text { management factor (Foster et al., } \\
\text { 2000; Nam et al., 2003) }\end{array}$ & 0 - 1 , unitless \\
\hline Meas_method & Soil erosion measure method & See Table 1 for details \\
\hline Field_scale & Scale of experiment field area & Catchment, watershed, plot etc. \\
\hline Field_area & Area of experiment field & $\mathrm{m}^{2}$ \\
\hline Measure_time & Time & When data was measured \\
\hline Measure_interval & Frequency of measurement & How many minutes per measurement \\
\hline Replication & Number of replications & \\
\hline Rainfall_intensity & Rainfall intensity & Could be both in the field or in the lab, $\mathrm{mm} \mathrm{h}^{-1}$ \\
\hline Rainfall_length & Rainfall length & How long the rainfall last, minute \\
\hline Rainfall_amount & Rainfall amount & $\begin{array}{l}\text { How much rainfall during the simulation, } \mathrm{mm} \\
\mathrm{h}^{-1}\end{array}$ \\
\hline Notes & Notes & Other important notes about the data in this row \\
\hline Data_source & Data source & Tips for where the data can be find in the paper \\
\hline Other_comments & Other comments & Other important comments \\
\hline
\end{tabular}


245 Table 4. Description for the quality flag field in the global soil erosion database (SoilErosionDB).

\begin{tabular}{|l|l|}
\hline Quality_flag & Description \\
\hline Q0 & Default/none \\
\hline Q1 & Estimated from figure \\
\hline Q2 & Data not reported in the original paper, but could be found from another study \\
\hline Q3 & Values estimated from a figure, with potential quality problem \\
\hline Q4 & Potentially useful values in the future \\
\hline Q5 & Values with potential problem \\
\hline Q6 & Data need to double check with original authors \\
\hline Q7 & Known problem \\
\hline Q8 & Duplicate \\
\hline Q9 & Inconsistency \\
\hline Q10 & Lack of useful data \\
\hline
\end{tabular}


Table 5. Description for the manipulation field in the global soil erosion database (SoilErosionDB).

\begin{tabular}{|c|c|c|}
\hline $\begin{array}{l}\text { Manipulation } \\
\text { Group }\end{array}$ & Manipulation & Comments \\
\hline Control & Control & default, if no manipulation can be identified \\
\hline \multirow[t]{2}{*}{$\begin{array}{l}\text { Changes in } \\
\text { precipitation }\end{array}$} & $\begin{array}{l}\text { Precipitation pattern } \\
\text { change }\end{array}$ & $\begin{array}{l}\text { e.g., same precipitation amount as control, but different } \\
\text { intensity and duration time }\end{array}$ \\
\hline & $\begin{array}{l}\text { Precipitation amount } \\
\text { change }\end{array}$ & More or less precipitation comparing with control \\
\hline Fertilization & Fertilization & e.g., $\mathrm{N}$ addition, slurry addition, compost \\
\hline \multirow[t]{6}{*}{$\begin{array}{l}\text { Agriculture } \\
\text { cultivation }\end{array}$} & Conventional tillage & $\begin{array}{l}\text { Traditional tillage (using plough, destroy soil structure a } \\
\text { lot) }\end{array}$ \\
\hline & Cover crop & One type of conservation management \\
\hline & No-till & One type of conservation management \\
\hline & Reduced tillage & One type of conservation management \\
\hline & Mulch & One type of conservation management \\
\hline & Conservation tillage & $\begin{array}{l}\text { Other conservation management other than cover crop, } \\
\text { no-till, reduced tillage, mulch, and ridge tillage }\end{array}$ \\
\hline Pollution & Pollution & Human activities related prolusion, such as acid rain \\
\hline PAM & PAM & Polyacrylamide application \\
\hline Fire & Fire & Disturbance by wildfire or artificial fire \\
\hline Multiple factors & Multiple factors & $\begin{array}{l}\text { Interactive and relative effects of two or more than two } \\
\text { manipulations }\end{array}$ \\
\hline Others & Others & Other treatment not included above \\
\hline
\end{tabular}




\section{References}

Berhe, A. A., Harte, J., Harden, J. W. and Torn, M. S.: The Significance of the Erosion-induced Terrestrial Carbon Sink, Bioscience, 57(4), 337-346, doi:10.1641/B570408, 2007.

Borrelli, P., Robinson, D. A., Fleischer, L. R., Lugato, E., Ballabio, C., Alewell, C., Meusburger, K., Modugno, S., Schütt, B., Ferro, V., Bagarello, V., Oost, K. V., Montanarella, L. and Panagos, P.: An assessment of the global impact of 21 st century land use change on soil erosion., Nat. Commun., 8(1), 2013, doi:10.1038/s41467-017-02142-7, 2017.

Flower, A., McKenna, J. W. and Upreti, G.: Validity and reliability of graphclick and datathief III for data extraction., Behav. Modif., 40(3), 396-413, doi:10.1177/0145445515616105, 2016.

Foster, G. R., Yoder, D. C., McCool, D. K., Weesies, G. A., Toy, T. J. and Wagner, L. E.: Improvements in science in RUSLE2., Improvements in science in RUSLE2., 2000.

García-Ruiz, J. M., Beguería, S., Nadal-Romero, E., González-Hidalgo, J. C., Lana-Renault, N. and Sanjuán, Y.: A meta-analysis of soil erosion rates across the world, Geomorphology, 239, 160-173, doi:10.1016/j.geomorph.2015.03.008, 2015.

Guo, Q., Hao, Y. and Liu, B.: Rates of soil erosion in China: A study based on runoff plot data, CATENA, 124, 68-76, doi:10.1016/j.catena.2014.08.013, 2015.

Ito, A.: Simulated impacts of climate and land-cover change on soil erosion and implication for the carbon cycle, 1901 to 2100, Geophys. Res. Lett., 34(9), doi:10.1029/2007GL029342, 2007.

Jian, J., Du, X. and Stewart, R. D.: A database for global soil health assessment., Sci. Data, 7(1), 16, doi:10.1038/s41597-020-0356-3, 2020a.

270 Jian, J., Du, X., Stewart, R., Tan, Z. and Bond-Lamberty, B.: jinshijian/SoilErosionDB: First release of SoilErosionDB, Zenodo, doi:10.5281/zenodo.4030875, $2020 \mathrm{~b}$.

Lal, R.: Soil erosion and the global carbon budget., Environ. Int., 29(4), 437-450, doi:10.1016/S01604120(02)00192-7, 2003.

Morgan, R. P. C.: Soil erosion and conservation, Soil Sci., 145(6), 461, doi:10.1097/00010694-

275 198806000-00011, 1988.

Nam, P. T., Yang, D., Kanae, S., Oki, T. and Musiake, K.: Global soil loss estimate using RUSLE model: the use of global spatial datasets on estimating erosive parameters., GEOINFORMATICS, 14(1), 49-53, doi:10.6010/geoinformatics.14.49, 2003.

Poesen, J.: Soil erosion in the Anthropocene: Research needs, Earth Surf. Process. Landforms, 43(1), 6484, doi:10.1002/esp.4250, 2017.

R Core Team: R: A language and environment for statistical computing. Computer software, R Foundation for Statistical Computing, Vienna, Austria., 2020. http://www.r-project.org/index.html.

Schubert, S. D., Suarez, M. J., Pegion, P. J., Koster, R. D. and Bacmeister, J. T.: On the cause of the 1930s Dust Bowl., Science, 303(5665), 1855-1859, doi:10.1126/science.1095048, 2004.

285 Tan, Z., Leung, L. R., Li, H.-Y., Tesfa, T., Zhu, Q. and Huang, M.: A substantial role of soil erosion in the land carbon sink and its future changes., Glob. Chang. Biol., 26, 2642-2655, doi:10.1111/gcb.14982, 2020 . 
Townshend, J. R. G. (ed. .: Improved global data for land applications. A proposal for a new high resolution data set. Report of the Land Cover Working Group of IGBP-DIS, Global Change Report (Sweden), 1992.

Toy, T. J., Foster, G. R. and Renard, K. G.: Soil Erosion: Processes, Prediction, Measurement, and Control, illustrated., John Wiley \& Sons., 2002.

Vanwalleghem, T., Gómez, J. A., Infante Amate, J., González de Molina, M., Vanderlinden, K., Guzmán, G., Laguna, A. and Giráldez, J. V.: Impact of historical land use and soil management change on soil erosion and agricultural sustainability during the Anthropocene, Anthropocene, 17, 13-29, doi:10.1016/j.ancene.2017.01.002, 2017.

Wilkinson, M. D., Dumontier, M., Aalbersberg, I. J. J., Appleton, G., Axton, M., Baak, A., Blomberg, N., Boiten, J.-W., da Silva Santos, L. B., Bourne, P. E., Bouwman, J., Brookes, A. J., Clark, T., Crosas, M., Dillo, I., Dumon, O., Edmunds, S., Evelo, C. T., Finkers, R., Gonzalez-Beltran, A. and Mons, B.: The

300 FAIR Guiding Principles for scientific data management and stewardship., Sci. Data, 3, 160018, doi:10.1038/sdata.2016.18, 2016.

Willmott and C. J.: Terrestrial Air Temperature and Precipitation: Monthly and Annual Time Series (1950-1996), WWW URL: http://climate.geog.udel.edu/ climate/html_pages/README.ghcn_ts.html, 2000.

305 Xu, X. Z., Xu, Y., Chen, S. C., Xu, S. G. and Zhang, H. W.: Soil loss and conservation in the black soil region of Northeast China: a retrospective study, Environmental Science \& Policy, 13(8), 793-800, doi:10.1016/j.envsci.2010.07.004, 2010.

Yue, Y., Ni, J., Ciais, P., Piao, S., Wang, T., Huang, M., Borthwick, A. G. L., Li, T., Wang, Y., Chappell, A. and Van Oost, K.: Lateral transport of soil carbon and land-atmosphere $\mathrm{CO} 2$ flux induced by water erosion in China., Proc Natl Acad Sci USA, 113(24), 6617-6622, doi:10.1073/pnas.1523358113, 2016.

Zhang, S., Li, Q., Zhang, X., Wei, K., Chen, L. and Liang, W.: Effects of conservation tillage on soil aggregation and aggregate binding agents in black soil of Northeast China, Soil and Tillage Research, 124, 196-202, doi:10.1016/j.still.2012.06.007, 2012.

Zhao, G., Mu, X., Wen, Z., Wang, F. and Gao, P.: Soil erosion, conservation, and eco-environment changes in the loess plateau of China, Land Degrad. Dev., doi:10.1002/ldr.2246, 2013. 